\title{
Carcinoma cuniculatum in maxillary gingiva mimicking verruciform xanthoma: a case report
}

\author{
Dongmei Jia, Yanhua Yang, Siqi Xu, Chen Jiang \\ Department of Pathology, Qingdao Municipal Hospital, Qingdao, China \\ Correspondence to: Chen Jiang, PhD. Department of Pathology, Qingdao Municipal Hospital, Qingdao 266071, China. Email: 1744392098@qq.com.
}

\begin{abstract}
Carcinoma cuniculatum (CC) is a rare and well-differentiated clinicopathological variant of squamous cell carcinoma (SCC) that is not common in head and neck. It is defined histologically by the infiltrative pattern of a deep, broad, and complex proliferation of stratified squamous epithelium with keratin cores and keratin-filled crypts. It has a propensity for local invasion and rare metastasis. This case report describes a 39-year-old man who was referred to our hospital with painful swelling in the right maxillary gingiva for 1 month and restriction of mouth opening for 1 week. Two biopsy examinations were negative for the diagnosis of malignancy, and the patient was misdiagnosed with verruciform xanthoma before an accurate diagnosis of CC. The biopsy reports were not in line with the imaging findings and clinical manifestations. Finally, he was diagnosed based on the combination of clinical manifestations and the pathological findings. Our case report provided a thorough clinical and histopathologic case of CC in maxillary gingiva, together with a brief review of the literature. In addition, we highlighted the difficulties in arriving at this uncommon diagnosis, and discussed the diagnosis of CC based on the combination of clinical manifestations and the pathological findings. To our knowledge, this is a very rare case of CC of the gingiva mimicking verruciform xanthoma.
\end{abstract}

Keywords: Carcinoma cuniculatum (CC); maxillary gingiva; squamous cell carcinoma (SCC); verruciform xanthoma; case report

Submitted Mar 30, 2021. Accepted for publication Aug 09, 2021.

doi: $10.21037 /$ tcr-21-552

View this article at: https://dx.doi.org/10.21037/tcr-21-552

\section{Introduction}

Carcinoma cuniculatum (CC), a rare, well-differentiated distinct clinicopathological variant of squamous cell carcinoma (SCC) (1), is first described by Aird on the sole of the foot in 1954 (2). Histologically, it is featured by infiltrative pattern of a deep, broad, and complex proliferation of stratified squamous epithelium with keratin cores and keratin-filled crypts, which results in information of tumor with a cuniculatum architecture similar to rabbit burrows. Nowadays, the diagnosis of CC is still a challenge in clinical practice as it usually mimics a variety of other lesions with an insidious onset and a benign course. To our best knowledge, rare CC cases showed features of verruciform xanthoma (3). Herein, we present a case of CC in the maxillary gingiva mimicking verruciform xanthoma, who was misdiagnosed in the preoperative biopsies at first. We present the following article in accordance with the CARE reporting checklist (available at https://dx.doi. org/10.21037/tcr-21-552).

\section{Case presentation}

All procedures performed in studies involving human participants were in accordance with the ethical standards of the institutional and/or national research committee(s) and with the Helsinki Declaration (as revised in 2013). Written informed consent was obtained from the patient for publication of this case report and accompanying images. A copy of the written consent is available for review by the editorial office of this journal. The study protocols were approved by the Ethical Committee of the Qingdao 

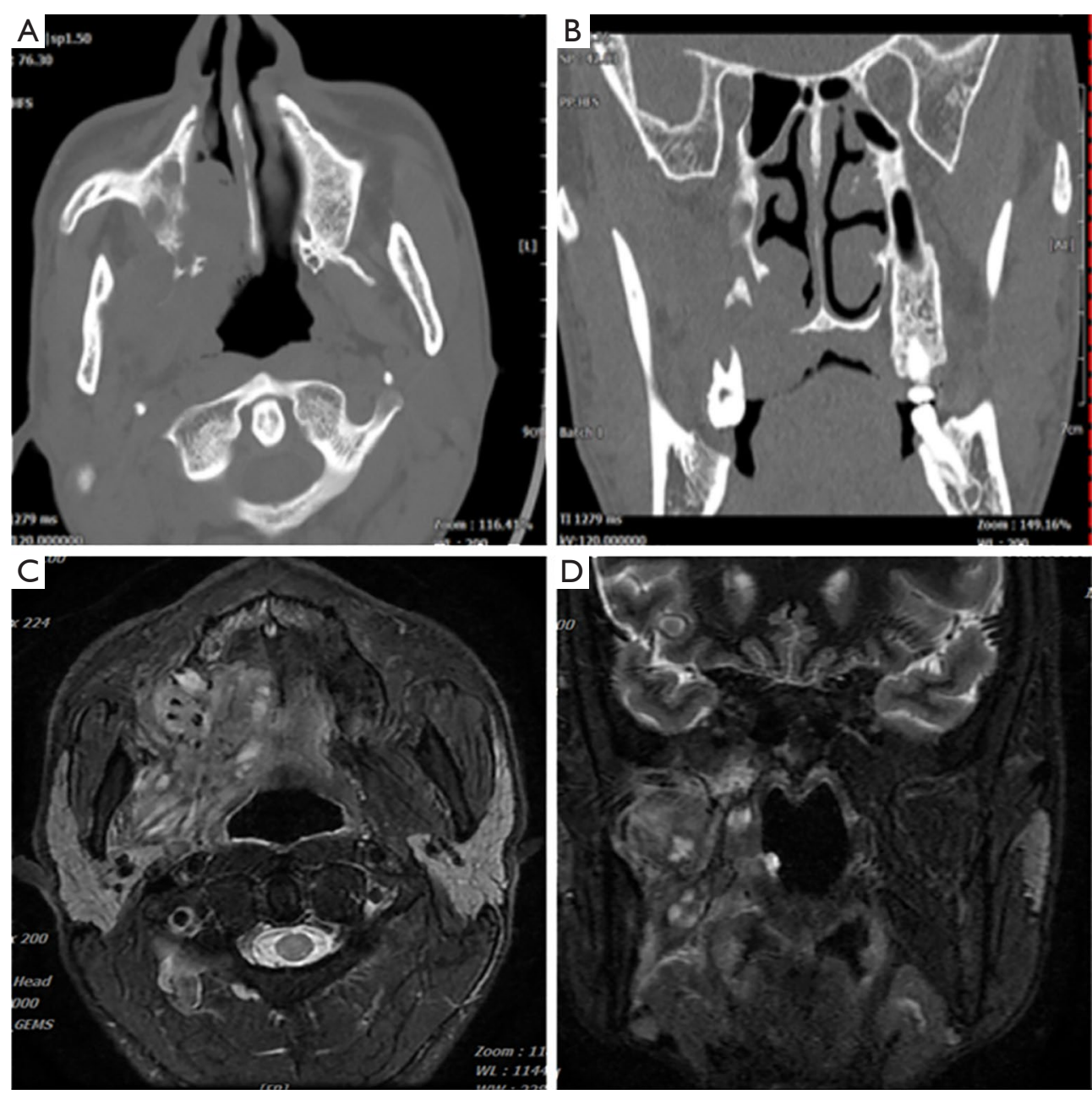

Figure $1 \mathrm{CT}$ and MRI imaging showed an osteolytic lesion of the right maxillary, hard palate and pterygoid process. (A) CT scan, axial view; (B) CT scan, coronal view; (C) axial T2-weighted MRI; (D) coronal T2-weighted MRI.

Municipal Hospital (approval No. 2021-051).

A 39-year-old male presented to our department with painful swelling in the right maxillary gingiva for 1 month and restriction of mouth opening for 1 week. He received no treatment within 1 month. On intra-oral examination, there was a red, ill-defined mass $(3.0 \mathrm{~cm} \times 2.0 \mathrm{~cm})$ with overlying superficial mucosal erosion between the right maxillary \#15 and \#17. Obvious touch pain was reported by the patient.

CT and MRI revealed an osteolytic lesion in the right maxillary region, hard palate and pterygoid process (Figure 1), as well as a soft tissue mass with a maximal crosssection of $4.8 \mathrm{~cm} \times 4.2 \mathrm{~cm}$. Thus, malignant tumor was considered. Initial biopsy was performed 4 weeks upon the presence of clinical presentations, which showed papillary surfaces and parakeratinized squamous epithelia with elongated epithelia rete ridges. This was characterized by the presence of foam cells in the connective tissue papillae. Then the patient was diagnosed with verruciform xanthoma. After taking the clinical presentation and radiographic evidence of bone invasion into consideration, the lesion was considered to be highly malignant.

The patient received subtotal maxillectomy. The findings of the intraoperative freezing section analysis were in line with the first biopsy. There was no radiographic evidence of cervical lymph node involvement. No cervical lymph nodes dissection was performed.

The resected specimen was sent for histopathological analysis. For the macroscopic observation on the surface, an irregular mass was seen to infiltrate the tissues from 

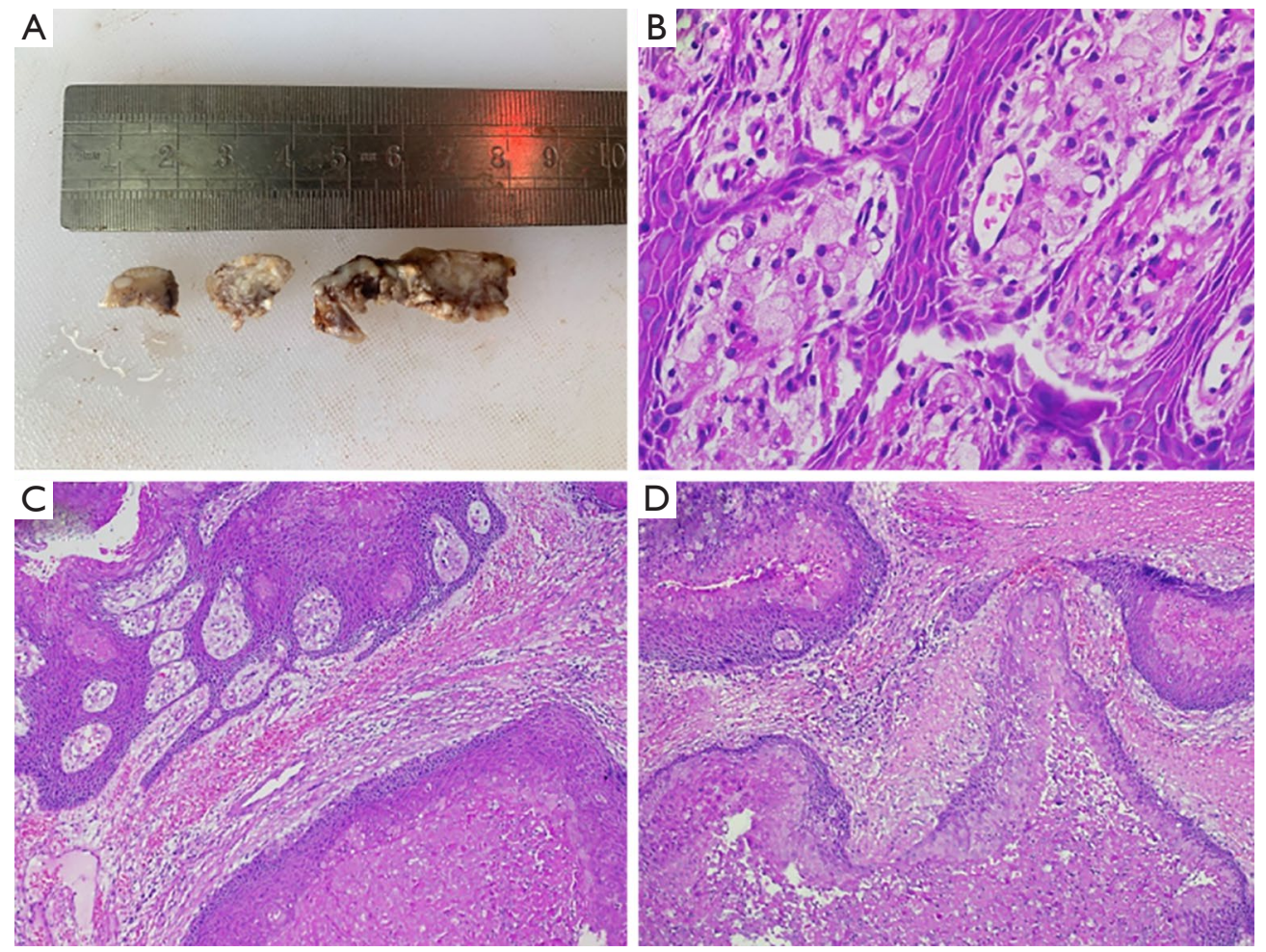

Figure 2 Macroscopic observation and histological staining of carcinoma cuniculatum. (A) The gross specimen showed a lumpy mass in the right maxillary. The incisal surface revealed irregular sinuses of tumor invaginations that went from surface-to-deep structure penetration. (B) The presence of foam cells in the connective tissue papillae between the epithelial rete ridges by H\&E staining. The images were observed under a magnification of 40x. (C) Histologic sections showed a prominent papillary growth pattern in the surface and a complex, branching networks of mostly bland, keratinizing squamous epithelium with cyst formation "burrowing into bone". The H\&E staining results were observed under a magnification of 10x. (D) The cysts were lined by benign-looking keratinizing squamous epithelium and filled with hyperkeratotic and parakeratotic cornified cells by H\&E staining under a magnification $10 x$.

surface to deep (Figure 2A). Histopathologic analysis indicated papillary surfaces and parakeratinized squamous epithelia, which was featured by the presence of massive foam cells in the connective tissue papillae between the epithelial rete ridges (Figure $2 B$ ) and multiple cysts formation of burrowing structures with various size and shape that deeply penetrated in the underlying tissues (Figure 2C,2D). The cysts were lined by well-differentiated keratinizing squamous epithelium, which showed mild to moderate cytologic atypia and few mitoses. The cavity was filled with hyperkeratotic and parakeratotic cornified cells combined with neutrophils (Figure 2D). Immunohistochemistry revealed that the tumour was negative for P16 and immunoreactive for P40 (Figure 3A) and CK. Immunohistochemical staining indicated a Ki67 positivity in $10 \%$ of cells (Figure $3 B$ ). The foam cells were immunoreactive for CD68. Immunohistochemistry for p53 indicated a wild type. Finally, the patient was diagnosed with oral CC mimicking verruciform xanthoma. After surgery, the patient was followed up for two months, and he was confirmed to be clinically and radiographically disease free.

\section{Discussion}

Based on the literature review, a total of 57 cases (4-25) with oral CC were obtained in Table 1 Oral CC has been reported in the English articles (Table 1). For the patient characteristics, there seemed to be a slight male preponderance (male: 35; female: 23). In addition, the patients diagnosed with oral CC were predominantly aged population (60 to 70 years old). For the treatment, surgery was the preferred treatment option as almost all the cases received surgery except one with no information on the 

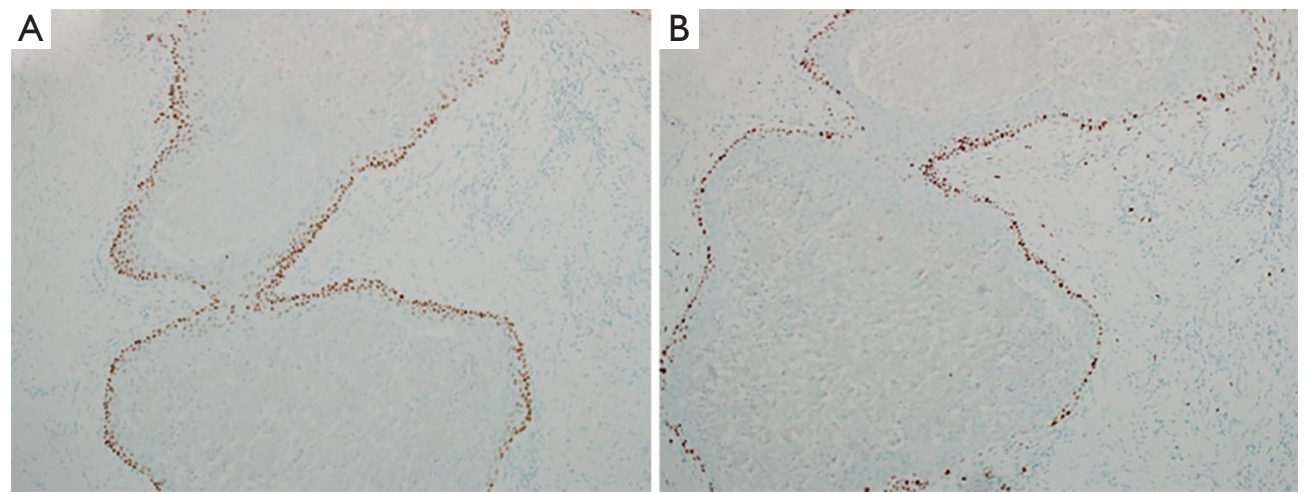

Figure 3 Immunohistochemical staining of p40 (A), Ki-67 (B) under a magnification 10x.

Table 1 Review of 57 published cases and the present case of Oral carcinoma cuniculatum

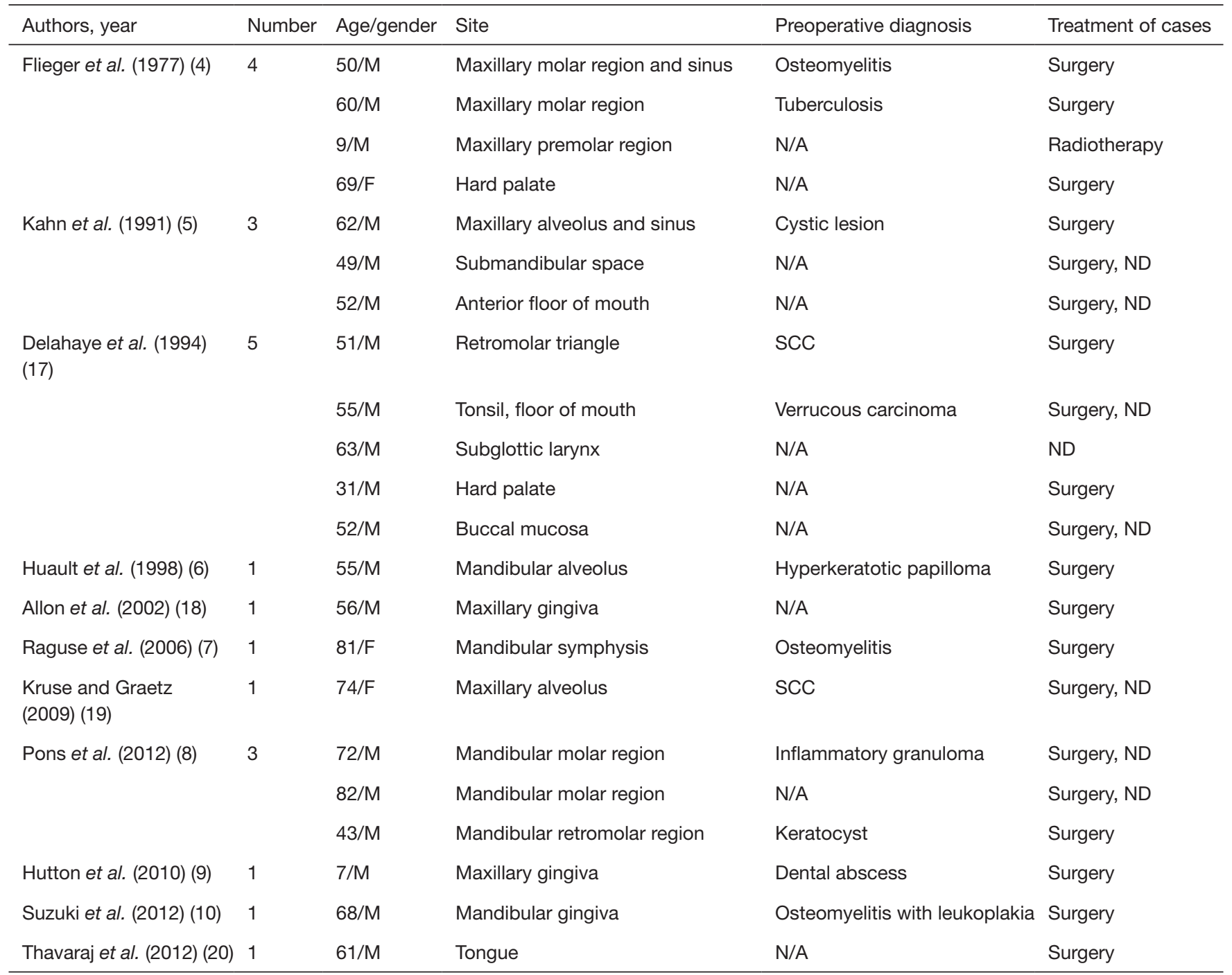

Table 1 (continued) 
Table 1 (continued)

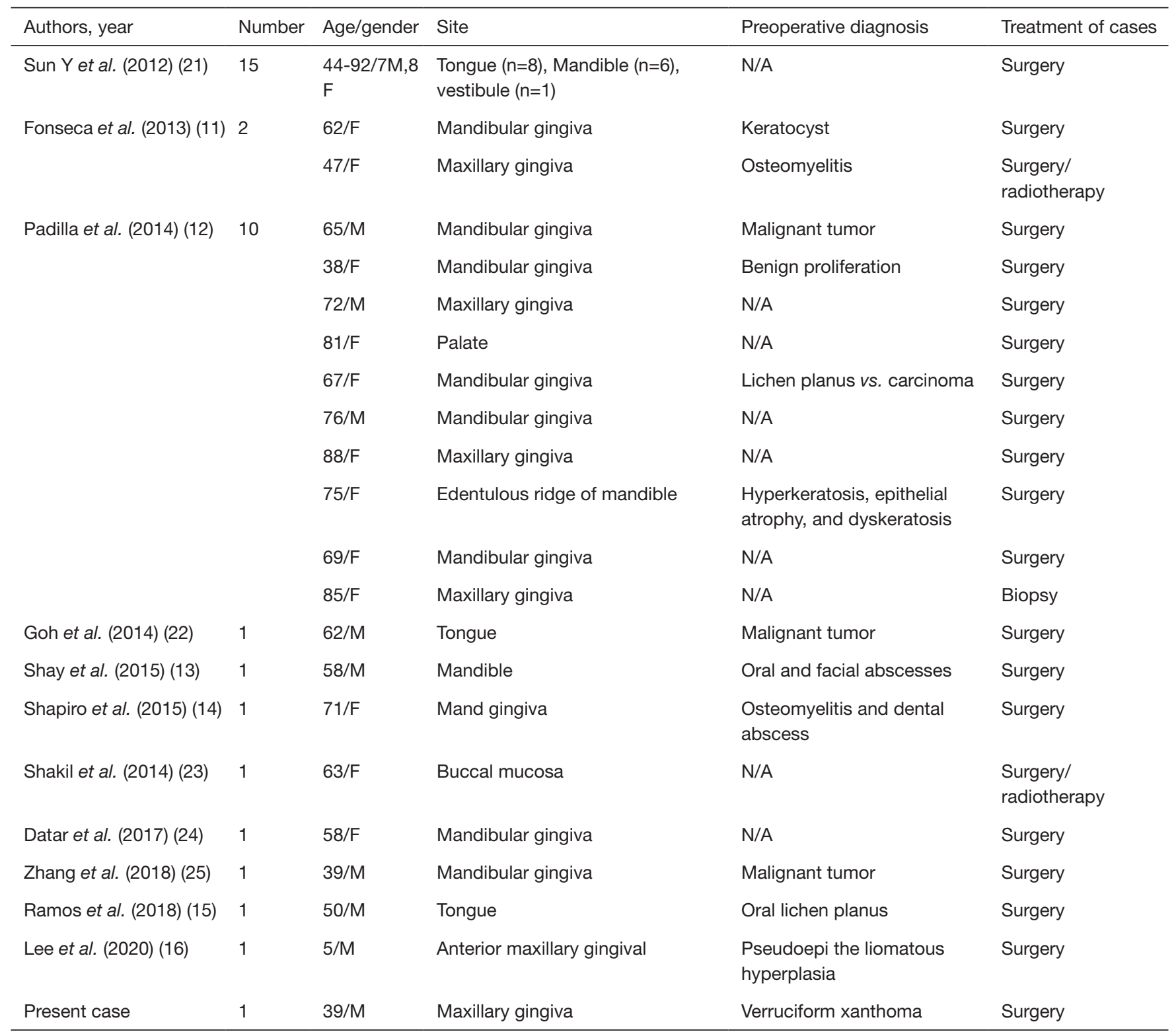

F, female; M, male; N/A, not available; ND, neck dissection.

treatment. Radiotherapy and chemotherapy are also utilized for some patients, but further investigations are required to validate its efficiency. In this case, the patient received subtotal maxillectomy. After surgery, he was followed up for two months, and was confirmed to be disease free. This indicated that surgery was feasible for treating oral CC.

The diagnosis of oral CC is still very difficult as it usually exhibits an insidious course mimicking benign lesion. In clinical practice, patients with oral CC often show similar manifestations with osteomyelitis, cystic lesion, lichen planus, papilloma or a dental abscess (4-16). The lesions were misdiagnosed with reactive or hyperplastic lesions in cases of a superficial or limited biopsy specimen of CC, a lack of cytologic atypia or combination of clinical manifestations. To our best knowledge, this is the first oral CC case mimicking pathological features of verruciform xanthoma. Based on the prognosis, CC must be distinguished from other clinical and microscopic 
overlapping tumors (e.g., well-differentiated SCC, verrucous carcinoma and solid variant of keratocystic odontogenic tumor) (17).

In summary, attention should be paid to its clinicpathologic characteristics for the accurate diagnosis in clinical practice. In this case report, we emphasized the importance of the combination of clinical and pathological findings in the diagnosis of the oral CC.

\section{Acknowledgments}

Funding: None.

\section{Footnote}

Reporting Checklist: The authors have completed the CARE reporting checklist. Available at https://dx.doi. org/10.21037/tcr-21-552

Conflicts of Interest: All authors have completed the ICMJE uniform disclosure form (available at https://dx.doi. org/10.21037/tcr-21-552). The authors have no conflicts of interest to declare.

Ethical Statement: The authors are accountable for all aspects of the work in ensuring that questions related to the accuracy or integrity of any part of the work are appropriately investigated and resolved. All procedures performed in studies involving human participants were in accordance with the ethical standards of the institutional and/or national research committee(s) and with the Helsinki Declaration (as revised in 2013). Written informed consent was obtained from the patient for publication of this case report and accompanying images. A copy of the written consent is available for review by the editorial office of this journal. The study protocols were approved by the Ethical Committee of the Qingdao Municipal Hospital (approval No. 2021-051).

Open Access Statement: This is an Open Access article distributed in accordance with the Creative Commons Attribution-NonCommercial-NoDerivs 4.0 International License (CC BY-NC-ND 4.0), which permits the noncommercial replication and distribution of the article with the strict proviso that no changes or edits are made and the original work is properly cited (including links to both the formal publication through the relevant DOI and the license). See: https://creativecommons.org/licenses/by-nc-nd/4.0/.

\section{References}

1. Thompson L. World Health Organization classification of tumours: pathology and genetics of head and neck tumours. Ear Nose Throat J 2006;85:74.

2. Aird I, Johnson HD, Lennox B, et al. Epithelioma cuniculatum: a variety of squamous carcinoma peculiar to the foot. Br J Surg 1954;42:245-50.

3. Kubik MJ, Rhatigan RM. Carcinoma cuniculatum: not a verrucous carcinoma. J Cutan Pathol 2012;39:1083-7.

4. Flieger S, Owiński T. Epithelioma cuniculatum an unusual form of mouth and jaw neoplasm. Czas Stomatol 1977;30:395-401.

5. Kahn JL, Blez P, Gasser B, et al. Carcinoma cuniculatum. Apropos of 4 cases with orofacial involvement. Rev Stomatol Chir Maxillofac 1991;92:27-33.

6. Huault M, Laroche C, Levy J, et al. Epithelioma cuniculatum. Apropos of a case in the anterior gingiva with involvement of the mandibular symphyseal bone and reconstruction using a fibular osteocutaneous flap and integrated implants. Rev Stomatol Chir Maxillofac 1998;99:143-8.

7. Raguse JD MH, Scholmann HJ, Bier J. Manifestation of carcinoma cuniculatum in the mandible. Oral Oncology Extra 2006;42:173-5.

8. Pons Y, Kerrary S, Cox A, et al. Mandibular cuniculatum carcinoma: apropos of 3 cases and literature review. Head Neck 2012;34:291-5.

9. Hutton A, McKaig S, Bardsley P, et al. Oral carcinoma cuniculatum in a young child. J Clin Pediatr Dent 2010;35:89-94.

10. Suzuki J, Hashimoto S, Watanabe K, et al. Carcinoma cuniculatum mimicking leukoplakia of the mandibular gingiva. Auris Nasus Larynx 2012;39:321-5.

11. Fonseca FP, Pontes HA, Pontes FS, et al. Oral carcinoma cuniculatum: two cases illustrative of a diagnostic challenge. Oral Surg Oral Med Oral Pathol Oral Radiol 2013;116:457-63.

12. Padilla RJ, Murrah VA. Carcinoma cuniculatum of the oral mucosa: a potentially underdiagnosed entity in the absence of clinical correlation. Oral Surg Oral Med Oral Pathol Oral Radiol 2014;118:684-93.

13. Shay S, Choy W, Christensen RE, et al. Extensive carcinoma cuniculatum of the mandible. Am J Otolaryngol 2015;36:446-50.

14. Shapiro MC, Wong B, O'Brien MJ, et al. Mandibular Destruction Secondary to Invasion by Carcinoma Cuniculatum. J Oral Maxillofac Surg 2015;73:2343-51. 
15. Ramos GO, Meyer GL, Visioli F, et al. Carcinoma cuniculatum in the tongue of a patient with oral lichen planus: Unusual presentation. Indian J Dent Res 2018;29:525-8.

16. Lee NV, Kang ETB, Senger C, et al. Oral cancer in a 5-year-old boy: a rare case report and review of literature. Oral Surg Oral Med Oral Pathol Oral Radiol 2020;130:e10-9.

17. Delahaye JF, Janser JC, Rodier JF, et al. Cuniculatum carcinoma. 6 cases and review of the literature. J Chir (Paris) 1994;131:73-8.

18. Allon D, Kaplan I, Manor R, et al. Carcinoma cuniculatum of the jaw: a rare variant of oral carcinoma. Oral Surg Oral Med Oral Pathol Oral Radiol Endod 2002;94:601-8.

19. Kruse AL, Graetz KW. Carcinoma cuniculatum: a rare entity in the oral cavity. J Craniofac Surg 2009;20:1270-2.

20. Thavaraj S, Cobb A, Kalavrezos N, et al. Carcinoma cuniculatum arising in the tongue. Head Neck Pathol 2012;6:130-4.

Cite this article as: Jia D, Yang Y, Xu S, Jiang C. Carcinoma cuniculatum in maxillary gingiva mimicking verruciform xanthoma: a case report. Transl Cancer Res 2021;10(10):4553-4559. doi: $10.21037 /$ tcr-21-552
21. Sun Y, Kuyama K, Burkhardt A, et al. Clinicopathological evaluation of carcinoma cuniculatum: a variant of oral squamous cell carcinoma. J Oral Pathol Med 2012;41:303-8.

22. Goh GH, Venkateswaran K, Leow PC, et al. Carcinoma cuniculatum of the esophagus and tongue: report of two cases, including TP53 mutational analysis. Head Neck Pathol 2014;8:261-8.

23. Shakil M, Mohtesham HI, Jose M, et al. Carcinoma cuniculatum of the oral cavity- A rare entity. J Adv Med Dent Scie 2014;2:124-26.

24. Datar UV, Kale A, Mane D. Oral Carcinoma Cuniculatum: A New Entity in the Clinicopathological Spectrum of Oral Squamous Cell Carcinoma. J Clin Diagn Res 2017;11:ZD37-9.

25. Zhang $\mathrm{C}, \mathrm{Hu} \mathrm{Y}$, Tian Z, et al. Oral carcinoma cuniculatum presenting with moth-eaten destruction of the mandible. Oral Surg Oral Med Oral Pathol Oral Radiol 2018;125:e86-93. 